\title{
Inflation Dynamics in the ABC (Argentina, Brazil and Chile) countries
}

\author{
Fernando Zarzosa Valdivia ${ }^{1}$
}

\section{Resumen}

Este trabajo evalúa la inercia y persistencia de la inflación y sus componentes para Argentina (dos períodos), Brasil y Chile utilizando modelos estacionales y fraccionalmente integrados autorregresivo de promedios móviles (modelo S-ARFIMA). Midiendo la inercia como la suma de los coeficientes autorregresivos encontramos que: (i) la inflación nivel general y los rubros vestimenta, salud, vivienda y servicios básicos y otros servicios exhiben mayor inercia en Argentina (segundo período) que en Chile y Brasil, (ii) la inercia en alimentos y bebidas en Chile es mayor que en Argentina (segundo período) y Brasil, y (iii) la inercia del rubro educación es mayor en Brasil que en Chile, que a la vez es mayor que en Argentina (segundo período). Midiendo la persistencia por el tamaño del coeficiente fraccionalmente integrado encontramos evidencia de memoria larga en la inflación general y en los rubros vestimenta y salud en Brasil y el rubro bebidas alcohólicas y tabaco de Chile. Adicionalmente mostramos que, ante un shock de precios a la inflación general, el cuarto (la media) de vida de ese shock dura 20, 3 y 15 (29, 15 y 13) meses en Argentina (segundo período), Brasil y Chile, respectivamente.

Palabras clave: inflación inercial, inflación sectorial, persistencia, ARIMA, ARFIMA

\section{Abstract}

This research analyses the inertia and persistence of headline and sectoral inflation for Argentina (two periods), Brazil and Chile using seasonal fractional integrated autoregressive moving average (S-ARFIMA model). Measuring inertia by the sum of the autoregressive coefficients, there is evidence of: (i) headline, clothing, health, housing and miscellaneous inertial inflation larger in Argentina (second period) than in Chile and Brazil, (ii) inertial inflation of food and beverages is larger for Chile than for Argentina (second period) and Brazil, and (iii) inertial inflation of education larger in Brazil than in Chile, which in turn is larger than in Argentina (second period). Measuring persistence by the size of the fractionally integrated coefficient, our results suggest long-memory or long-dependence of Brazilian headline, clothing and health inflation, and Chilean alcoholic beverages. We show also that the quarter-life of headline inflation occurs in 20,3 and 15 months in Argentina (second period), Brazil and Chile, while its half-life takes 29, 15 and 13 months, respectively.

Keywords: inflation inertia, sectoral inflation, persistence, ARMA, ARFIMA.

JEL: E31, E37, C5

DOI: https://doi.org/10.46553/ensayos.3.2.2020.p77-99

Fecha de recepción: 30/10/2019; Fecha de aceptación: 05/05/2020

\footnotetext{
${ }^{1}$ Universidad Nacional de Córdoba and Universidad Católica de Córdoba. Mail: zarzosa.fernando@gmail.com
} 


\section{Introduction}

Inflation, when appropriately measured, is a key variable for the evaluation of past economic performance. Inflation forecast are an important input to monetary policy and to a myriad of private decisions (Stock and Watson, 2016, p. 770), such as the formulation of economic policy, and the price setting behaviour of decision makers (workers, employers, savers and investors). Also, higher inflation rates are associated to stock return volatility, small and less liquid equity markets, small financial sector and less economic growth.

The degree of success of efforts to achieve price stability has varied among Argentina, Brazil and Chile, the so-called ABC countries. While the former is experiencing doubledigit inflation, the latter exhibit moderate rates (one-digit inflation). Policymakers should know the insights of short and long run effects of exogenous shocks on headline or sectoral-level inflation, the so-called inertia and persistence, respectively. Sectoral inflation refers to the price variation of the component-specific basket of goods of the consumer price index, e.g. food and beverages, clothing, housing, household and equipment, health, transport and communication, recreation, education and miscellaneous goods and services prices.

Countries with different speed of sectoral inflation adjustments could struggle to control inflation. "An inflation shock entails costly adjustment in the economy when inflation is inertial. When aggregate demand responds to interest rate changes with a lag and inflation is inertial, the central bank will not be able to offset aggregate demand and aggregate supply shocks immediately and adjustment will therefore be costly" (Carlin and Soskice, 2009, p. 32). Thus, inertia and persistence are important because they affect "the output costs of lowering inflation back to the target, often described as the sacrifice ratio" (Roache, 2014, p.1).

Despite their importance, especially in highly inflationary countries, the dynamics of inflation are mainly focused on the CPI (Consumer Price index) or GDP (Gross Domestic Product) indexes. In line with Buelens (2012), this paper assesses the dynamics of headline and sectoral inflation for the ABC countries. Taking into account, only, the intrinsic behaviour of each inflation series, a seasonal autoregressive moving average (S-ARMA) model is selected on the basis of the lowest Schwarz information criterion. It is extended to a S-ARFIMA (seasonal fractionally integrated autoregressive moving average) model when its fractionally coefficient is statistically significant up to the $10 \%$ significance level. Up to now, ARFIMA models applied to inflation series assume, in general, in an ad-hoc basis the order of the autoregressive lag polynomial; see see Franses and Ooms (1997), Gadea and Mayoral (2006), Franta et al. (2007), Balcilar et al. (2016) and Gomes and Leme (2011).

Regarding inflation dynamics, when the effects of exogenous price shocks a) are instantaneous, there is no inflation dynamics; b) of the short-run nature, there is inflation inertia (the aggregate autoregressive coefficient is different from zero, but lower than one), which means that the responses of inflation, periods ahead, to an impulse or exogenous shock eventually disappear; c) have long-memory or long-term dependence (the fractionally integrated coefficient is smaller than $|0.5|$ ), there is persistence, which means that the responses of price changes, periods ahead, to an impulse have lasting effects, although finite; d) are 'less non-stationary', there is mean 
reversion, but at a very slow peace (fractionally integrated coefficient larger than $|0.5|)$; and e) are non-stationary, inflation exhibits unit root behaviour.

Our contribution comes from a comprehensive measurement of the inertia and persistence of headline and sectoral inflation for the $A B C$ countries, as well as of the length (quarter, half and full life) of a shock to die out. Regarding headline inflation, for instance: a) the inertia in Argentina is larger than in Brazil, 0.864 vs 0.363, although the latter exhibits persistence behaviour, 0.345 ; b) the quarter (half) of a life of an exogenous shock occurs in a year and a half (30 months) in Argentina, while it occurs in a quarter of a year (15 months) in Brazil; c) the full life of an exogenous shock is larger in Brazil than in Argentina (seven years vs four years and a half); and d) there is, in Chile, no evidence of inertia or persistence behaviour.

Our results suggest that the inconsistent inflation targeting monetary policy, with fiscal dominance, applied in Argentina in 2016 was not expected to generate a major break on inflationary expectations. Thus, a $27 \%$ the inertial inflation was expected for the year 2016, a rate higher than its target, "25\%" (BCRA, 2016, p. 31). We also find evidence that an impulse (exogenous shock) keeps adding up price increases up to one year before it starts to stabilize in the cases of Argentinean headline, food and beverage, transport and household and equipment inflation and Brazilian food and beverage, transport and housing and equipment inflation. Also, the average full (50\%) life of an exogenous shock to all inflation components in Argentina die out in 86 months (16 months).

The remainder of the paper is organized as follows: Section 2 reviews the inflation dynamics literature. Section 3 defines headline and sectoral inflation, provides the data sources and analyses the corresponding stylized facts. Section 4 presents the applied methodology, the evidence regarding headline and sectoral inflation inertia and persistence and the quarter-half-and-full life of a shock. Section 5 concludes and provides insights for future research.

\section{Literature review}

The pattern of inflation is often at the heart of economic policy decision-making since it influences the economic agents' price-setting behaviour through its effect on the real interest rate, the inflation risk premia and the expected inflation rate. "Decisionmakers need to have a view on the likely future path of inflation when taking measures that are necessary to reach their objective. Yet, while being indispensable to many decision-making agents, forming inflation expectations is generally both complex and costly: indeed, inflation forecasting requires an understanding of economic relationships, econometric modelling tools, access to data and other information" (Buelens, 2012, p.4).

High inflation distorts the relative prices signalling role in the allocation of resources. There are various inflation theories, which differ in their assumptions, methodologies, diagnosis or prescriptions. Relying heavily in Totonchi (2011), it can be said that a) the monetarists argue that the money supply is the "dominant, though not exclusive" determinant of both the level of output and prices in the short run, and of the level of prices in the long run; b) the demand-pull inflation theory of Keynes suggests that a policy that causes decrease in each component of total demand is effective in reduction 
of pressure demand and inflation; c) cost-push inflation is caused by wage increases enforced by unions and profit increases by employers; d) supply increase related to demand-push, even if abundant unemployment, is impossible or slow due to structural inflation factors; e) under rational expectations people do not consistently make the same forecasting errors and, therefore, only through price surprises central banks can increase output and employment levels; f) the neoclassical new synthesis assumes endogenous price level in an economy with price stickiness in the short-run (new Keynesian assumption), and supply shocks that explain mainly real economic activity (the new classical real business cycle theory); and g) the new political economy provides fresh perspectives on the relations between timing of elections, performance of policy maker, political instability, policy credibility and reputation, and the inflation process itself. Heymann (1986) provides an additional survey of inflation theories.

The amount of effort assigned to understand inflation dynamics has been directly related to its severity throughout history. Canavese (1985, p.352) suggests that an exogenous price shock generates hyperinflation when the share of government expenditure in the GDP is larger than the degree of monetization. Following SaavedraRivano (1988), inflation dynamics are fueled by the working capital and distributive conflicts relationship. From an historical point of view, Mohaded and Gasparin (2011, p.2) argue that inflationary problems are not mere consequences of bad economic decisions, but of various conflicts between groups that hold political power.

The Great Inflation period (1965-1982), a period in which inflation rose above normal levels throughout developed countries, encouraged many attempts to deepen the understanding of inflation. Cogley and Sargent (2001) apply VAR models to study the dynamic of the U.S. inflation and unemployment after WW II. They observe a direct and close relationship between inflation mean, volatility and persistence: inflation persistence increased and became variable during the 1970 's, when inflation rose, while it decreased in the 1980 s and 1990s when anti-inflationary policies were pursued. Batini (2006) finds that inertial inflation in Europe did not change significantly during 1970-2000 even though there are different country-specific inflation patterns. $\mathrm{He}$ also finds that European countries face high inflation inertia. Following Kouretas and Wohar (2012) and Levin and Piger (2004), much of the empirical findings assessing high inflation inertia in developed countries are sensible to changes in econometric techniques.

The Great Recession of 2008-2009 appears to have changed the inflation dynamics. Dany-Knedlik and Holtemöller (2017) find that, in the European Union countries, the inflation level, volatility and persistence have changed after 2009. Berganza et al. (2016) suggest that some structural inflation patterns might have been changing since the outbreak of the crisis, although there is no conclusive evidence yet. Buelens (2012) highlights that inflation forecasting has become more difficult after the financial crisis. The effects of the downfall of the international financial markets in the period 2008 2009 on Argentina were mild because these markets were closed to it. Brazil "managed to weather the international financial crisis reasonably well, despite having been severely hit initially" (Barros, 2010, p.1).

Measuring inertial inflation by the sum of the autoregressive coefficient of $A R(p)$ models, Capistrán and Ramos-Francia (2006) find, for the ten largest Latin American countries, a high degree of inertia; Chile exhibit the lowest inflation inertia, while Argentina and Brazil the largest. They also suggest that inertial inflation decreased in 
Argentina and Brazil, but it does not seem to have changed in Chile. Noriega and Ramos-Francia (2009) find evidence of changes in the inertial inflation in Argentina and Brazil, but not in Chile. Based on an AR(1) model for the period 2000-2013, Roache (2014) finds that half-life of headline inflation is larger in Chile than in Brazil. Based also on AR(p) models, D'Amato and Garegnani (2013) and D'Amato et al. (2007) find, in line with Cogley and Sargent (2001), a direct relationship between Argentinean headline inflation and its persistence (1961-2006), with large persistence increases during periods of high inflation periods.

Based on ARFIMA models, a) Franses and Ooms (1997) analyze the inflation (retail price index based) persistence for the UK (1955M02-1989M01), b) Gadea and Mayoral (2006) find evidence of headline inflation persistence in the OECD countries, c) Franta et al. (2007) evaluates the persistence of GDP-based inflation in the Euro Area and new member countries, d) Balcilar et al. (2016) show that headline inflation in South Africa is more volatile and persistent during high inflation episodes relative to low inflation episodes and e) Gomes and Leme (2011) find that Brazilian headline exhibit inertia and persistence behaviour.

Following Stock and Watson (2016, p. 770), more precise measures of trend inflation can be obtained using disaggregated sectoral inflation and estimate their relationship by a dynamic factor model with time varying coefficients and stochastic volatility. Buelens (2012) disaggregates headline inflation in five main components. Bermingham and D'Agostino (2011) study lower levels of disaggregation. There is no recent literature regarding the dynamics of headline and specific-component inflation in the ABC countries.

\section{II.1. Inflation (sectoral and headline) and financial sector}

Ozturk and Karagoz (2012, p.81) states that "by creating uncertainty and financial market frictions, high rates of inflation make the financial system inefficient in allocating resources". Although the Fisher condition implies equal variations between the nominal interest rate and the inflation rate and, therefore, assets returns constant in an inflationary regime, the evidence suggest "that post-war data for the US and other industrialized countries exhibit a significant negative correlation between inflation and real stock returns. This negative correlation between inflation and real stock returns is often termed the stock return-inflation puzzle" (Gallagher and Taylor, 2002, p.147).

Regarding the effects of inflation on the financial markets, Boyd et al. (2001) suggests that a) higher rates of inflation are associated with greater inflation and stock return volatility, b) higher inflation implies less long-run financial activity, and equity markets will be smaller and less liquid and c) several inflation thresholds may characterize the relationship between inflation and financial sector conditions. Ozturk and Karagoz (2012, p.81) adds that it can be expected that high rates of inflation have negative impact on financial development as well as on economic growth. It is then important knowing not only whether exogenous shocks have long run or permanent rates on headline inflation, but also on sectoral inflation. 


\section{Inflation: Data sources and stylized facts}

\section{1. Inflation concepts and measurement}

Inflation, defined as a sustained increase in the overall price level, can be classified as a) creeping inflation when it is positive, but lower than $3 \%$ annual, b) walking inflation when it is between $3 \%$ and $10 \%$ annual, c) galloping inflation when it is higher than $10 \%$ annual, d) chronic inflation when it is higher than $10 \%$, but lower than $20 \%$ monthly, and e) "hyperinflation defined on the basis of Cagan's criterion as an inflation rate of at least $50 \%$ per month (or $12.975 \%$ per annum); a modest threshold would be $20 \%$ per month (or $892 \%$ per year)" (Agénor, 2004, p.208).

Following Gillis et al. (1987, pp.329-331) price inflation, can be considered, for economies with high inflationary processes, in its 'moderate' form (annual inflation rates between 8 and 12 percent) corrosive, but not fatal, while runaway inflation (hyperinflation) is always recognized as severely destructive. They define additionally chronic (inflation rate greater than 25 percent per year, but less than 50 percent for three years or more) and acute inflation (inflation that exceeds the 50 percent for three or more consecutive years).

Based on the inflationary history during the 70 s and the $80 \mathrm{~s}$, Gutierrez and Dabús (1989) define four phases for the Argentinean inflationary cycle. A phase with a) an inflation rate between $10 \%$ and $12 \%$ per month, with low variability, b) an inflation rate larger than $10 \%-12 \%$ with peaks of $20 \%$, with increasing variability, c) an inflation rate larger than $30 \%$ per month, without showing fluctuations, but an accelerating trend towards the hyperinflation, and d) an abrupt reduction of the inflation, reaching values between $1 \%$ to $3 \%$ per month.

Consumer price index (CPI) based headline inflation is a weighted average of the variation of a set of component-specific price indices (based on sub-baskets of goods and services). The weights correspond to the share of each type of good in the consumer expenditure. Table 1 provides the list of the different types of goods included in the consumer price indices of the $A B C$ countries. 
Table 1: Component-specific price indexes types in the $A B C$ countries

\begin{tabular}{|c|c|c|c|}
\hline References & Argentina & Brazil & Chile \\
\hline CPI-1 & \multirow{2}{*}{ Food and beverage* } & \multirow{2}{*}{ Food and beverage } & $\begin{array}{c}\text { Food and non-alcoholic } \\
\text { beverage }\end{array}$ \\
\hline CPI-2 & & & $\begin{array}{c}\text { Alcoholic beverage and } \\
\text { Tobacco }\end{array}$ \\
\hline CPI-3 & Clothing & Clothing & Clothing \\
\hline CPI-4 & Health & Health & Health \\
\hline CPI-5 & Education & Education & Education \\
\hline CPI-6 & \multirow{2}{*}{$\begin{array}{l}\text { Transport and } \\
\text { Communication* }\end{array}$} & Transport & Transport \\
\hline CPI-7 & & Communication & Communication \\
\hline CPI-8 & Housing & Housing & Housing \\
\hline CPI-9 & Household and Equipment & Household and Equipment & Household and Equipment \\
\hline CPI-10 & $\begin{array}{l}\text { Miscellaneous goods and } \\
\text { Services }\end{array}$ & \multirow{3}{*}{$\begin{array}{c}\text { Miscellaneous goods and } \\
\text { Services }\end{array}$} & $\begin{array}{c}\text { Miscellaneous goods and } \\
\text { Services }\end{array}$ \\
\hline CPI-11 & \multirow{2}{*}{ Recreation* } & & Recreation and Culture \\
\hline CPI-12 & & & Hotels and Restaurants \\
\hline
\end{tabular}

Note: CPI-1 in Argentina and Brazil include CPI-1 and CPI-2. CPI-6 in Argentina includes CPI-6 and CPI-7. CPI-10 in Brazil includes CPI-10, CPI-11 and CPI-12. CPI-11 in Argentina includes CPI-11 and CPI-12.

\section{2. Data sources}

Monthly data are collected for Argentina (two samples, January 1995 - December 2001, November 2005 and April 2019), Brazil (January 1995 - April 2019) and Chile (December 2009 - April 2019). ${ }^{2}$ In Argentina, the first and second samples are provided from the National Institute of Statistics and Census (INDEC, Instituto Nacional de Estadísticas y Censos) and the Statistics Bureau of San Luis Province, respectively. After 2006, the CPI's data from the INDEC become unreliable since the credibility of the INDEC suffered a major setback after the government intervened and manipulated the data, including prices. ATE-INDEC (2014) provides a description of the INDEC independence impairment, while Berumen and Veker (2011) analyse the reliability of CPI's data after the INDEC intervention. Alternative inflation sources do not disaggregate the CPI as the data from San Luis Province does.

Chilean consumer price indices are provided by the National Institute of Statistics (INE). The Brazilian Extended National Consumer Price Index (IPCA) is provided by the Brazilian Institute of Geography and Statistics (IBGE, Instituto Brasileiro de Geografia e Estatística). Brazilian consumer-based price index patterns are also reflected by the extended National CPI-15 (IPCA-15) and Special Extended National CPI (IPCA-E) indexes, but the IPCA can be easily benchmarked to the Argentinean and Chilean consumer price indexes.

\footnotetext{
${ }^{2}$ In Argentina, two samples are considered and analysed separately due to the shortcomings of extrapolating inflation series of different sources and regions, especially because inflation dynamics changed from a period of price stability up to 2001, even deflationary, to an inflationary process thereafter. Adding structural breaks to single headline or sectoral inflation series would reflect variations in the construction of the series rather than on their variability or dynamics.
} 


\section{III.3. Stylized facts}

Inflation targeting has been implemented in Brazil, Chile, and Colombia (1999), Mexico (2001), Peru (2002) and Uruguay (2007); see Cottani and Oliveros-Rosen (2016). Argentina applied it, without success between 2016 and 2018. Inflation rates in the ABC countries were highly volatile before the 1990s, but after anti-inflationary measures in the early 1990s, it decreased and remained low. In Argentina, however, inflation is on upward trend from the end of 2001 onwards.

Table 2 and Figure 1 provide some insights into the behaviour of headline or sectoral inflation rates of the $A B C$ countries. ${ }^{3}$ For instance, it tells us that a) the average of the Argentinean monthly headline inflation was -0.018 between January 1995 and December 2001, but $1.993 \%$ after November 2005, and b) the annual (tri-annual) headline inflation rate was 23.6\% (71.6\%), in average, between November 2005 and April 2019.

Table 2: Mean Inflation Rates (in percentages)

\begin{tabular}{|c|c|c|c|c|c|c|}
\hline & \multicolumn{2}{|c}{ Argentina } & Brazil & \multicolumn{2}{c|}{ Chile } & \multicolumn{2}{c|}{ Argentina } \\
\hline & $1995-2001$ & $2005-2019$ & $1995-2019$ & $2009-2019$ & \multicolumn{2}{c|}{$2005-2019$} \\
\cline { 2 - 7 } & Monthly & Monthly & Monthly & Monthly & Annual & Tri-annual \\
\hline $\mathrm{i}$ & $-0,018$ & 1,993 & 0,559 & 0,258 & 23,678 & 71,27 \\
\hline $\mathrm{i}-1$ & $-0,104$ & 2,111 & 0,535 & 0,397 & 24,905 & 73,879 \\
\hline $\mathrm{i}-2$ & & & & 0,635 & & \\
\hline $\mathrm{i}-3$ & $-0,29$ & 1,973 & 0,38 & $-0,626$ & 25,536 & 73,409 \\
\hline $\mathrm{i}-4$ & 0,081 & 1,743 & 0,623 & 0,32 & 20,906 & 64,628 \\
\hline $\mathrm{i}-5$ & 0,033 & 2,263 & 0,702 & 0,412 & 26,411 & 80,687 \\
\hline $\mathrm{i}-6$ & 0,238 & 1,843 & 0,554 & 0,175 & 21,887 & 64,628 \\
\hline $\mathrm{i}-7$ & & & 0,782 & $-0,087$ & & \\
\hline $\mathrm{i}-8$ & 0,004 & 2,049 & 0,737 & 0,338 & 24,646 & 73,921 \\
\hline $\mathrm{i}-9$ & $-0,072$ & 1,904 & 0,291 & 0,172 & 22,948 & 69,545 \\
\hline $\mathrm{i}-10$ & 0,022 & 1,98 & 0,629 & 0,4 & 23,905 & 73,678 \\
\hline $\mathrm{i}-11$ & 0,032 & 1,858 & & $-0,076$ & 22,435 & 69,319 \\
\hline $\mathrm{i}-12$ & & & & 0,465 & & \\
\hline
\end{tabular}

Note: $\mathrm{i}$ and $\mathrm{i}-j(j=1, \ldots .$, and 12$)$ refer, respectively, to headline and sectoral inflation rates related to the corresponding CPI and CPI-j price indexes.

Argentina experienced price stability during 1995 and 2001. In this period, headline inflation as well as food and beverage, clothing and household and equipment prices were deflationary; their mean annual rate were $-0,216 \%,-1,24 \%,-3,42 \%$ and $0.86 \%$, respectively. By the end of 2001 , Argentinean debt load become unsustainable and its exchange rate regime collapsed with the consequent increase of headline and sectoral inflation. Argentina experienced walking inflation (lower than $10 \%$ ) up to March 2007. Figure 1 suggest that, between March 2007 and July 2012, inflation was galloping (higher than 10\%), showing signs of chronic inflation (higher than $25 \%$, but lower than 50\% tri-annual). By August 2012 Argentinean inflation become acute (higher than $50 \%$ tri-annual and for more than three years), with a maximum of $95 \%$ (between May 2013 and May 2016). Argentinean sectoral price indexes follow, in general, the behaviour of the consumer price index.

\footnotetext{
${ }^{3}$ See Appendix A for a detailed graphical analysis.
} 
Figure 1: Headline Inflation in the $A B C$ countries
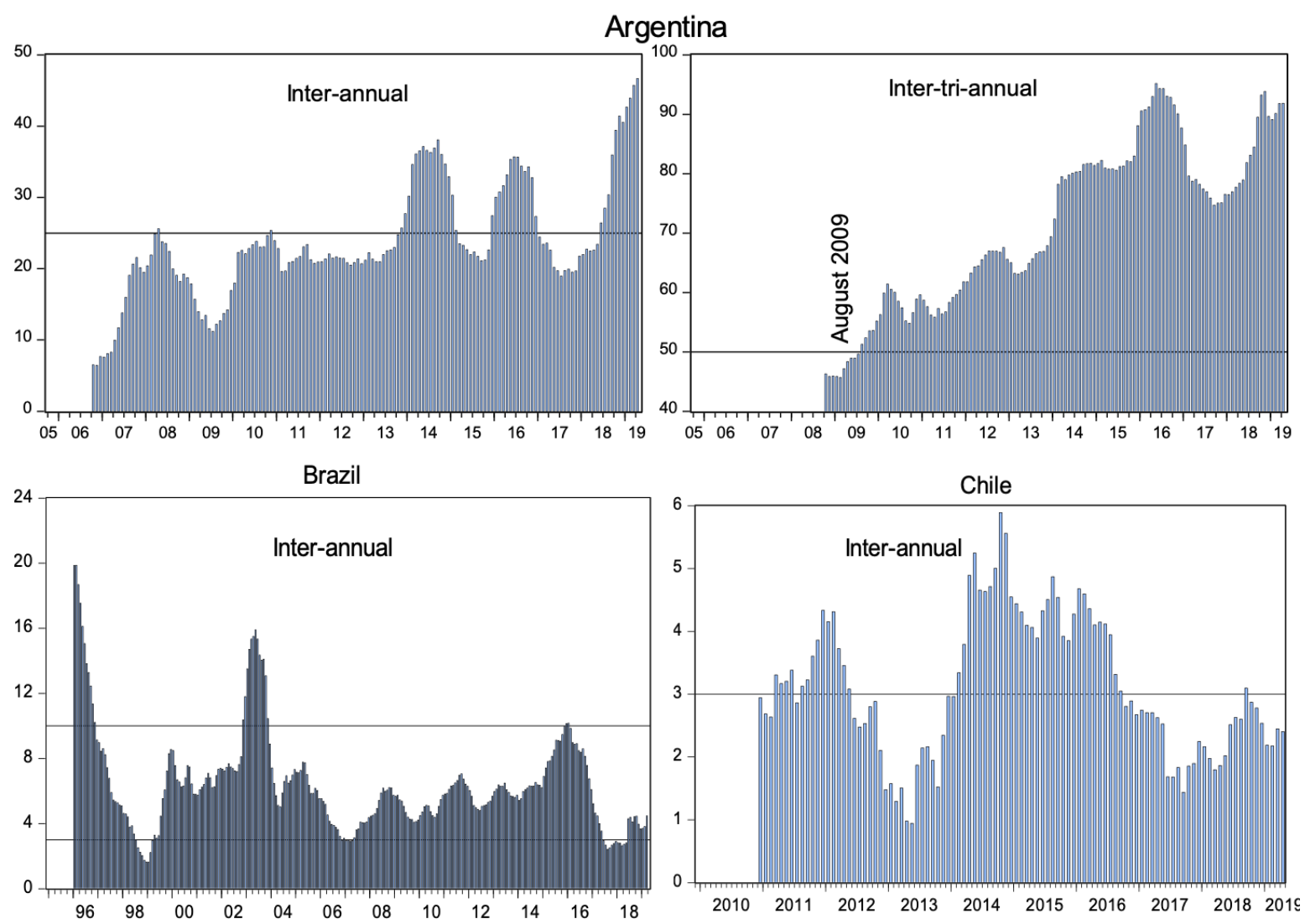

Note: Argentinean headline inflation rates refer to the second sample only (November 2005 to April 2019).

Although Brazilian inflation has been controlled, it has experienced mainly periods of walking inflation (annual average headline inflation equal to $6.42 \%$ ), except in the periods of creeping inflation (June 1998 - April 1999 and June 2017 - June 2018) and galloping inflation (between January to November 1996 and November 2002 to November 2003).

The Chilean experience has been highly successful in controlling inflation, reaching inflation rates of one-digit inflation. Between January 2010 to April 2019, Chile exhibits moderate inflation rates with an annual inflation average of $3.11 \%$. It has mainly experienced creeping inflation, except in the periods of walking inflation (March 2011 May 2012 and February 2014 - September 2016). It is worth nothing that clothing, communication and recreation and culture inflation rates show a negative trend as well as negative average rates, see Table 2.

\section{Methodology and results}

In this section, the dynamics of headline and sectoral inflation are evaluated based on autoregressive moving average models selected by the Schwarz Information Criterion (SIC). 


\section{IV.1. Unit root tests}

Before any regression analysis is performed, it is essential to identify the order of integration of headline inflation and its components. "Whether inflation series are best treated as stationary or non-stationary has not yet been conclusively resolved. Test results naturally vary from country to country, but also depend heavily on the particular statistical methods adopted" (Charemza et al., 2004, p.2).

In this section the Dickey-Fuller (ADF), the Kwiatkowski, Phillips, Schmidt and Shin (KPSS) and the Phillips-Perron (PP) unit root tests are applied to the corresponding inflation series. The ADF and the PPP unit root tests assume a null of a series having a unit root. The PP with respect to the ADF unit root test is a robustness test to general forms of heteroskedasticity in the error term, controls for serial correlation and it does not have to specify the length for the regression. The KPSS is a test of the null hypothesis that an observable series is stationary around a deterministic trend Kwiatkowski et al., 1992, p.159); in other words, the null is that the corresponding series is trend stationary.

Table 3 displays the observed statistics associated to the corresponding unit root tests. The PP unit root test rejects the null hypothesis, in all cases, at the $1 \%$ significance level. In general, the ADF unit root test rejects the null at the $1 \%$ cases. The KPSS unit root test cannot reject the null of trend stationarity at the $1 \%$, except for a) the Argentinean headline inflation and household and equipment and recreation sectoral inflation (sample, 2005M10-2019M4), and b) the Brazilian communication and Chilean recreation and culture specific-component inflation. The contrast results between the KPSS and the other unit root test could reflect the existence of long-memory processes in series with mean reverting properties. 
Table 3: Observed ADF, KPSS and PP Statistics

\begin{tabular}{|c|c|c|c|c|c|c|c|c|c|c|c|c|}
\hline \multirow{3}{*}{ Inflation } & \multicolumn{6}{|c|}{ Argentina } & \multirow{2}{*}{\multicolumn{3}{|c|}{ Brazil }} & \multirow{2}{*}{\multicolumn{3}{|c|}{ Chile }} \\
\hline & \multicolumn{3}{|c|}{ First Sample } & \multicolumn{3}{|c|}{ Second Sample } & & & & & & \\
\hline & ADF & KPSS & $\mathrm{PP}$ & ADF & KPSS & $\mathrm{PP}$ & ADF & KPSS & $\mathrm{PP}$ & ADF & KPSS & $\mathrm{PP}$ \\
\hline i & $-5.89 * * *$ & $\begin{array}{l}0.547 * \\
*\end{array}$ & $-9.05 * * *$ & $-6.25 * * *$ & $\begin{array}{l}0.887 \\
* * *\end{array}$ & $-6.17 * * *$ & $-7.13^{* * *}$ & $0.429 *$ & $-6.88 * * *$ & $-8.86 * * *$ & 0.143 & $-8.85 * * *$ \\
\hline $\mathrm{i}-1$ & $-8.19 * * *$ & 0.248 & $-8.19 * *$ & $-8.17 * * *$ & $\begin{array}{l}0.372 \\
*\end{array}$ & $-8.19 * * *$ & $-8.72 * * *$ & 0.1099 & $-7.25 * * *$ & $-7.66 * * *$ & 0.342 & $-7.32 * * *$ \\
\hline $\mathrm{i}-2$ & & & & & & & & & & $-12.1 *$ & $\begin{array}{l}0.532 * \\
*\end{array}$ & $-12.1 * * *$ \\
\hline$i-3$ & $-6.64 * * *$ & 0.202 & $-9.59 * * *$ & $-19.1 * * *$ & $\begin{array}{l}0.484 \\
* *\end{array}$ & $-20.0 * * *$ & -1.937 & $\begin{array}{l}0.512 * \\
*\end{array}$ & $-12.2 * * *$ & $-12.1 * * *$ & $\begin{array}{l}0.506 * \\
*\end{array}$ & $-10.1 * * *$ \\
\hline $\mathrm{i}-4$ & $-9.61 * * *$ & 0.126 & $-10.9 * * *$ & $-13.8^{* * *}$ & $\begin{array}{l}0.66 * \\
*\end{array}$ & $-24.0 * * *$ & $-6.16 * * *$ & $\begin{array}{l}0.406 * \\
*\end{array}$ & $-6.46 * * *$ & -2.266 & 0.166 & $-12.5^{* * *}$ \\
\hline$i-5$ & $9.16 * * *$ & $\begin{array}{l}0.731 * \\
*\end{array}$ & $-9.18 * * *$ & $-8.3 * * *$ & $\begin{array}{l}0.413 \\
*\end{array}$ & $-34.1 * * *$ & $-5.56 * * *$ & $0.462 *$ & $-13.7 * * *$ & $12.48^{* * *}$ & 0.069 & $-20.43 * * *$ \\
\hline$i-6$ & $-8.36 * * *$ & 0.281 & $-8.35 * * *$ & $-15.5 * * *$ & $\begin{array}{l}0.72 * \\
*\end{array}$ & $-15.63 * * *$ & $-10.8 * * *$ & $\begin{array}{l}1.026 * \\
* *\end{array}$ & $-10.8^{* * *}$ & -2.46 & 0.325 & $-10.2 * * *$ \\
\hline $\mathrm{i}-7$ & & & & & & & $-3.69 * * *$ & $\begin{array}{l}0.863 * \\
* *\end{array}$ & $-14.6 * * *$ & $-10.05 * * *$ & $\begin{array}{l}0.494 * \\
*\end{array}$ & $-9.82 * * *$ \\
\hline $\mathrm{i}-8$ & $-7.49 * * *$ & 0.233 & $-7.41 * * *$ & $-11.8 * * *$ & $\begin{array}{l}1.16 * \\
* *\end{array}$ & $-11.8 *$ & $-4.16 * * *$ & $\begin{array}{l}0.497 * \\
*\end{array}$ & $-8.13 * * *$ & $-9.77 * * *$ & 0.067 & $-10.7 * * *$ \\
\hline$i-9$ & $-5.54 * * *$ & $0.58 * *$ & $-5.53 * * *$ & $-5.59 * * *$ & $\begin{array}{l}0.819 \\
* * *\end{array}$ & $-10.2 * * *$ & $-8.03 * * *$ & 0.173 & $-7.89 * * *$ & $-10.6 * * *$ & 0.276 & $-8.46 * * *$ \\
\hline $\mathrm{i}-10$ & $-7.71 * * *$ & 0.084 & $-7.69 * * *$ & $-12.4 * * *$ & $\begin{array}{l}0.586 \\
* *\end{array}$ & $-19.5^{* * *}$ & $-13.5^{* * *}$ & 0.162 & $-13.7 * * *$ & $-7.9 * * *$ & 0.147 & $-20.2 * * *$ \\
\hline $\mathrm{i}-11$ & -1.75 & 0.2505 & $-10.0 * * *$ & $-12.2 * * *$ & $\begin{array}{l}1.09 * \\
* *\end{array}$ & $-12.2 * * *$ & & & & -1.51 & $\begin{array}{l}0.94 * * \\
*\end{array}$ & $12.1 * * *$ \\
\hline $\mathrm{i}-12$ & & & & & & & & & & $-4.89 * * *$ & $\begin{array}{l}0.534 * \\
*\end{array}$ & $-8.36 * * *$ \\
\hline
\end{tabular}




\section{IV.2. S-ARMA and S-ARFIMA models}

Although inflation rates are stationary (in line with the PP unit root test), they might be influenced by their past levels (AR) or by systematic fluctuations errors (MA) incurred when estimating them. The dynamic behaviour of headline and sectoral inflation rates are evaluated assuming that the data generating process follows a $\mathrm{n}$ extended seasonal autoregressive-moving-average (S-ARMA) process. Formally:

$$
\left(1-\sum_{i=1}^{p^{j}} \alpha_{i}^{j} L^{j}\right)\left(1-\alpha_{s} L^{S}\right) \pi_{i}^{j}=\left(1-\sum_{i=1}^{q^{j}} \beta_{i}^{j} L^{j}\right)\left(1-\beta_{s} L^{j}\right) e^{j}+\sum_{i_{s}=1}^{12} \gamma_{i_{s}}^{j} D_{i_{s}}^{j}+\sum_{i=1}^{k^{j}} \delta_{i}^{j} D_{i}^{j}
$$

where: $\pi$ refers to the inflation rate (or the specific component price level variation) of the country $j, p$ and $q$ indicate the autoregressive and moving average orders (up to the twelve order), respectively. $P$ and $Q$ indicate the seasonal autoregressive and moving average terms (set up to order one, with $\alpha$ and $\beta$ estimates). $D_{i_{s}}^{j}(i=1,2, \ldots, 12$ ) refers to the deterministic seasonal dummy variables (variables with one in the corresponding month, while zero otherwise), $D_{i}^{j}$ refers to the added shift or economic policy dummy variables (variables with one in the period in which the observed error exceeds 2.5 times its standard deviation, but zero elsewhere).

Equation (1) includes, additionally, deterministic monthly seasonal dummy variables as well as shift or economic policy dummy variables. Non-seasonal dummy variables aim to correct the impact that exogenous shocks or economic policies might have on the data generation process and, therefore, on the selection procedure of the corresponding information criteria. ${ }^{3}$

Following (Gujarati, 1995, p.735), ARMA models are a-theoretical models that analyse "the probabilistic, or stochastic, properties of economic time series on their own under the philosophy 'let the data speak for themselves'." There are various methodologies to select the $(p, q)$ and $(P, Q)$ values; the stochastic AR and MA seasonality, 12 in our case, assumes "that the dynamic behaviour of the data is equal across seasons, i.e. the covariance function is constant over time" (Franses and Ooms, 1997, p.117). The Box-Jenkings procedure selects, $\mathrm{p}$ and $\mathrm{q}$ values on basis of the Autocorrelation and Partial Autocorrelation Functions. Sample variability of the correlation and partial autocorrelations may, however, lead to patterns that are not easily associated with a particular order and, therefore, imply a significant degree of subjectivity when identifying $\mathrm{p}$ and $\mathrm{q}$. Up to now, the order of AR models applied to inflation series are of an ad-hoc order. In this research the Schwarz (SIC) information criteria ${ }^{4}$ is used to select, for each series, the best $\operatorname{ARMA}(p, q)(P, Q)$ model out of 676 alternatives. Each model is estimated by the Maximum likelihood method, optimized by the BroydenFletcher-Goldfarb-Shanno (BFGS) algorithm. Assuming shifts (outliers) ${ }^{5}$ of deterministic nature, the following procedure has been applied: a) an S-ARMA model is selected, b) for the highest residual that exceeds 2.5 times in absolute value its standard deviation, a shift/economic policy dummy variable has been added to the

\footnotetext{
${ }^{4}$ The SIC criterion leads to more parsimonious models than the Akaike information criterion since it penalizes more the inclusion of explanatory variables. The SIC criterion is defined as follows: $I C=-2 L(p+q+P+Q) \log (T)$

where $L$ is the maximum value of the Log likelihood of the corresponding $S-A R M A(p, q)(P, Q)$ model, $T$ refers to the sample size.

${ }^{5}$ The list of outliers as well as the inflation shifts due to the financial crisis are available upon request.
} 
model; c) the best model out of 676 models has been again selected; d) the procedure is repeated, in general, until there are no residuals larger in absolute value than 2.5 times their standard deviation; and e) in cases in which the residual were not normal, the Box-Cox transformation method is applied and steps a) to d) are repeated.

Inflation and sectoral inertia are measured by the aggregate AR coefficients. Following Gadea and Mayoral (2006), measuring persistence, by the sum of the AR coefficients, could lead to erroneous conclusions if fractional integration is present. Consequently, the long-range dependency or long memory of the involved series is evaluated by extending each of the selected models as an ARFIMA model. Formally:

$$
\left(1-\sum_{i=1}^{p^{j}} \alpha_{i}^{j} L^{j}\right)(1-L)^{d}\left(1-\alpha_{s} L^{s}\right) \pi_{i}^{j}=\left(1-\sum_{i=1}^{q^{j}} \beta_{i}^{j} L^{j}\right)\left(1-\beta_{s} L^{j}\right) e^{j}+\sum_{i_{s}=1}^{12} \gamma_{i_{s}}^{j} D_{i_{s}}^{j}+\sum_{i=1}^{k^{j}} \delta_{i}^{j} D_{i}^{j}
$$

where $d$ is the fractionally integrated parameter. Only when $-0.5<d<0.5$ the series are stationary, otherwise they are not stationary (even if the series are mean reverting).

The autocorrelations of stationary ARMA series decay exponentially, the autocorrelations of fractionally integrated series have hyperbolic decreases. ARFIMA models "allow a high degree of persistence without assuming a unit root (i.e. I(0)) character of the process" (Franta et al., 2007, p.15). The ARMA processes are "processes of short-memory in the sense where the shock at a given moment is not sustainable and does not affect the future evolution of time series" (Bourbonnais and Maftei, 2012, p.2). The long memory process, but not infinite, is an intermediary case, in that the effect of a shock has lasting consequences for future values of the time series, but it will find its "natural" equilibrium level (Mignon, 1997). When the fractionally integrated coefficient is larger than 0.5 in absolute value, the corresponding serie is not stationary, even if it has no unit roots. It is said, in this cases, that "the non-stationary ARFIMA model is" less non-stationary" than an integrated process of order one" (Pérez and Ruiz, 2002, p.405). Only when the fractional coefficient is statistically significant, the ARFIMA model is considered. Inflation and sectoral inflation persistence (anti-persistence) is measured by the positive (negative) fractionally integrated coefficient.

Inertia and persistence measures do not, however, tell us much about the length of the adjustment process of headline and sectoral inflation in response to shocks. The impulse response function associated to each ARMA or ARFIMA model measures the changes in the future responses of the corresponding variable when it is shocked by an impulse. Gomes and Leme (2011, p.292) suggest that the coefficients of the impulse response of an ARMA process disappear geometrically, but coefficients of the impulse response of an ARFIMA process decay gradually and slow (they decrease with a hyperbolic rhythm at a rate which is lower than the exponential rate of the process ARMA). The intermediate ARFIMA case, called anti-persistent by Mandelbrot corresponds to alternations of increases and decreases in the process. This behaviour refers to the so-called "Joseph effect" by reference to the Bible (Bourbonnais and Maftei, 2012, p.4). In this research, we also estimate the impulse response associated to the selected ARMA (or ARFIMA) model and measures how long it takes for $\theta$ percent of the effects of a shock to die out. 


\section{IV.3. Estimation Results}

The estimated results are summarized in Tables 4 and 5 . Table 4 displays the best $\mathrm{S}$ ARMA/SARFIMA models, the aggregate AR coefficients and the fractionally integrated coefficients when necessary. In line with Capistrán and Ramos-Francia (2006), D'Amato and Garegnani (2013) and D'Amato et al. (2007), headline and sectoral inertial inflation is measured by the sum of the autoregressive coefficients. A shortcoming of estimating inflation inertia by the sum of the autoregressive coefficients is that it might signal wrong inertial process when various autoregressive coefficients differ from sign. For instance, inertia of Argentinean transport and communication prices seems low (aggregate AR equal to -0.038 and non-statistically significant at the $10 \%$ level), but its dynamics say otherwise, $\operatorname{AR}(1)$ and $\operatorname{AR}(2)$ equal to 0.322 and 0.360 (both statistically significant at the $1 \%$ level), respectively.

The adjustment process of the different price indexes varies between countries as well as between the different component-specific price indexes. Table 5 displays, based on impulse response functions ${ }^{6}$ for a span of 100 periods, a) the half-life, defined as the number of periods that a shock needs to vanish by 50 percent, b) the quarter-life defined as the number of periods required for the response of a time series, to its own shock, to be quartered and c) the 'full-life' defined as the periods that a shock needs to disappear. Appendix B displays the impulse response functions associated to Table 5.

Inflation dynamics of the headline and sectoral inflation in the $A B C$ countries varies between countries and specific components. As expected, Argentina is a two-country case; its two samples exhibit, in all inflation levels, different dynamics, with larger inertia and persistence in the period 2005-2019. Argentinean headline, health, education, housing and recreation and culture (price stability period, 1995-2001) inflation do not have autoregressive dynamics. In Chile, headline and six sectoral inflation rates do not have autoregressive dynamics, but five of these cases exhibit seasonal autoregressive dynamics. ${ }^{7}$ Also, Argentina (price stability period, 1995-2001) and Chile exhibit one and four cases, respectively, of inflation persistence, ${ }^{8}$ respectively. Headline inflation inertia is larger in Argentina (second sample) than in Brazil; as a result, the quarter and half-life of a shock is larger in Argentina (20 and 29 months, respectively) than in Brazil ( 3 and 15 months, respectively). Due to the persistence behaviour of Brazilian headline inflation, however, the full life of a shock to it last longer than in Argentina (second sample), 75 months vs 55 months. Our results for Brazil suggest lower headline inertia and persistence, $\operatorname{AR}(1)=0.363$ and $d=0.345$, than Gomes and Leme (2011, p. 298) results, $A R(1)=0.7$ and $d=0.435$, for the period 1999M07 - 2010M12. Additionally, in contrast to Roache (2014), the half-life of headline inflation in Brazil is slightly larger than in Chile

\footnotetext{
${ }^{6}$ The impulse response function associated to each model of Table 4 provides better insights about the dynamics of headline and sectoral inflation since it shows the responses, periods ahead, to an impulse or exogenous shock.

7 Seasonal dynamics imply larger periods of adjustment in response to a shock because the effects of a shock only have effect each 12 months. For example, the effects of a headline inflation shocks die out in 2 months in Argentina (first sample), while 37 months in Chile.

${ }^{8}$ The persistence cases suggest that, even if there is price stability, temporal exogenous shocks do not disappear in the short-run, but last longer, although they disappear in the long-run (their fractional integrated coefficients are lower than 0.5).
} 
Table 4: Best S-ARFIMA Models: $(p, q)(P, Q)$ values, aggregate AR and fractionally integrated coefficients

\begin{tabular}{|c|c|c|c|c|c|c|c|c|c|c|c|c|}
\hline \multirow[t]{2}{*}{ Countries } & \multicolumn{6}{|c|}{ Argentina } & \multicolumn{3}{|c|}{ Brazil } & \multicolumn{3}{|c|}{ Chile } \\
\hline & \multicolumn{3}{|c|}{$1995-2001$} & \multicolumn{3}{|c|}{$2005-2019$} & & & & & & \\
\hline Model & \multicolumn{3}{|c|}{ S-ARFIMA } & \multicolumn{3}{|c|}{ S-ARFIMA } & \multicolumn{3}{|c|}{ S-ARFIMA } & \multicolumn{3}{|c|}{ S-ARFIMA } \\
\hline Inflation & S-ARMA & $\sum A R$ & d & S-ARMA & $\sum A R$ & $d$ & S-ARMA & $\sum A R$ & $d$ & S-ARMA & $\sum A R$ & $d$ \\
\hline$\overline{\mathrm{i}}$ & $(0,1)(0,1)$ & & & $(2,0)(1,1)^{\mathrm{BC}}$ & $0.864 * * *$ & & $(1,0)(0,0)$ & $0.363 * * *$ & $0.345^{* * *}$ & $(0,0)(1,1)$ & & \\
\hline$i-1$ & $(1,0)(0,1)$ & $0.409 * * *$ & & $(1,0)(1,1)$ & $0.547 * * *$ & & $(1,1)(1,1)$ & $0.454 * * *$ & & $(1,1)(1,1)$ & $-0,65 * * *$ & \\
\hline$i-2$ & & & & & & & & & & $(1,3)(1,1)$ & $0.522 * *$ & $0.499 * *$ \\
\hline$i-3$ & $(2,2)(0,1)$ & $0.301 * * *$ & & $(1,1)(0,0)$ & $0.91 * * *$ & & $(1,1)(1,0)$ & 0.489 & $0.291 * *$ & $(0,6)(1,0)$ & & \\
\hline $\mathrm{i}-4$ & $(0,1)(0,0)$ & & & $(1,3)(1,1)$ & $0.995 * * *$ & & $(1,0)(0,1)$ & $0.293^{*} *$ & $0.199 * *$ & $(0,0)(0,0)$ & & \\
\hline$i-5$ & $(0,0)(0,1)$ & & & $(5,3)(1,0)^{\mathrm{BC}}$ & 0.289* & & $(5,2)(1,0)$ & $0.959 * * *$ & & $(1,1)(1,1)$ & $0.805^{* * *}$ & \\
\hline$i-6$ & $(2,0)(0,1)$ & -0.038 & & $(1,1)(1,1)$ & -0.123 & $\begin{array}{c}0.499 * \\
* *\end{array}$ & $(1,0)(1,1)$ & $0.345 * * *$ & & $(1,0)(1,1)$ & $0.323 * * *$ & \\
\hline $\mathrm{i}-7$ & & & & & & & $(0,6)(0,0)$ & & & $(0,0)(1,1)$ & & \\
\hline $\mathrm{i}-8$ & $(0,0)(0,1)$ & & & $(3,1)(0,0)^{\mathrm{BC}}$ & 0.985 & $\begin{array}{c}0.331^{*} \\
*\end{array}$ & $(4,0)(0,0)$ & $0.815 * * *$ & & $(0,1)(0,1)$ & & \\
\hline$i-9$ & $(1,0)(0,0)$ & -0.037 & $\begin{array}{c}0.328 \\
* *\end{array}$ & $(1,1)(1,1)^{\mathrm{BC}}$ & 0.052 & $\begin{array}{c}0.499 * \\
* *\end{array}$ & $(1,1)(0,0)$ & $0.927 * * *$ & $-0.372 *$ & $(1,1)(0,0)$ & $0.934 * * *$ & \\
\hline $\mathrm{i}-10$ & $(1,0)(1,1)$ & $0.311^{* *}$ & & $(3,1)(1,1)$ & $0.977 * * *$ & $\begin{array}{c}0.491 * \\
*\end{array}$ & $(1,1)(0,1)$ & 0.177 & $0.337 * * *$ & $(0,0)(1,1)$ & $0.147 *$ & $0.453 *$ \\
\hline $\mathrm{i}-11$ & $(0,0)(0,1)$ & & & $(2,3)(1,1)$ & $-0.843 * * *$ & & & & & $(0,0)(0,1)$ & & $0.151 * *$ \\
\hline $\mathrm{i}-12$ & & & & & & & & & & $(1,1)(0,0)$ & 0.034 & $0.385^{*}$ \\
\hline
\end{tabular}

Notes: (i) The first and second number of each cell refer to the $p$ and $q$ order of the best selected ARMA model, while the third and fourth number of each cell refer to the seasonal AR and MA terms, respectively. (ii) A variable follows an S-ARFIMA processes when the coefficient $d$ is different from zero at the $10 \%$ significance level (iii) $\sum$ refers to the summation sign, with $\sum$ reflecting the aggregation of the autoregressive coefficients. BC refers to the cases in which the Box-Cox transformation method was applied. (iv) The null of normal residuals is rejected at the $1 \%$ level for the Argentinean i-4 and i-5 (first sample), i-3, i-5, i8 , i-9 (second sample), the Brazilian headline inflation and the Chilean i-5 series. Normality test applied on the residuals are available upon request. (v) The results for the Brazilian i-7 series refer to the subsample 1999M01-2019M03, the sample 1995M01-1998M12 exhibits a deterministic behaviour.(vi) The list of added dummy variable and the Durbin and Watson test for autocorrelation (assuming that there are no lagged dependent variables) available upon request.

(vii) $\left(^{*}\right),\left({ }^{* *}\right)$ and $\left({ }^{* *}\right)$ indicate that the corresponding estimate is statistically different from zero at the $10 \%, 5 \%$ 
The inflation inertia behaviour of food and beverage in Argentina (both samples) and Brazil tells us that an exogenous shock today will increase next month food and beverage prices by more than $40 \%$. The adjustment process will occurs faster in Argentina than in Brazil, see the second row of Table 5. The autoregressive coefficient of Chilean food prices is negative, it implies a cyclical dynamic behaviour after a shock has hit it; its half-life occurs in approximately one year. There is evidence of persistence in Chilean beverage prices, with a half-life of a shock around 5 years.

Inertia of clothing and health prices are larger in Argentina (second sample) than in Brazil. In both cases, there is evidence of persistence behaviour. The half-life of a shock to clothing (health) prices is shorter (larger) in Argentina (second sample) than in Brazil. Inertia of education prices is lower in Argentina (second sample) than in Chile and Brazil, with no persistence behaviour in none of these countries. As expected, the half and full life of shocks to education prices die out in Argentina (second sample) faster than in Chile and Brazil. Transport and communication in Argentina (second sample) exhibit persistence behaviour, the regulatory framework, before 2015, on these prices might be related to its slow adjustment process in response to a shock. Communication prices exhibit neither inertia nor persistence behaviour.

While inflation of housing utilities exhibits only persistence behaviour in Argentina (second sample), it exhibits only inertia in Brazil; it has no dynamics in Chile. Half-life of the adjustment process due to an exogenous shock to housing utilities prices takes 13 months in Argentina (second sample), but only 7 months in Brazil. The inflation targeting measures taken for Argentina in 2016 could not be successful because the half-life of the adjustment process due to higher prices of gas and electricity occur within a year.

Household equipment sectoral inflation shows, in both Argentinean samples, a longmemory or hyperbolic decay adjustment behaviour when an exogenous shock hit it. In Brazil, it shows anti-persistent behaviour or Joseph effects. In Chile, it has only inertial behaviour, with 8 (32) months necessary for 50\% (full life) a shock to die out. Miscellaneous goods and services exhibit inertia and persistence in Argentina (second sample) and Chile, with a half-life adjustment process due to a shock shorter in Argentina than in Chile.

The life cycle of headline and sectoral inflation in Argentina (second sample) is shorter than in Brazil, except for transport, housing and household and equipment. It might reflect the fact that nominal inertia currently in Argentina is lower with respect to Brazil. Half-life of headline and sectoral inflation, for all cases, is larger in Brazil than in Chile, except for communication, household and miscellaneous goods and services.

\section{Conclusions and further research}

This paper analyses the inflation dynamics in Argentina, Brazil and Chile. Inflation dynamics are assessed by the best seasonal autoregressive moving average models, selected by the Schwarz information criteria. Additionally, the selected models are extended to an autoregressive fractionally integrated moving average when the fractional integrated coefficient is statistically different from zero up to the $10 \%$ 
significance level. Headline and specific-component inflation exhibit different behaviour within a country and between countries. The Argentinean two samples (1995M012001M12, 2005M10-2019M04) reflects a 'two-country' case, inertial inflation and persistence has sharply increased between these two periods.

Measuring inertial inflation by the sum of the autoregressive coefficients, we find evidence of a) headline, clothing, health, housing and miscellaneous inertial inflation is larger in Argentina than it is in Chile and Brazil, b) inertial inflation of food and beverages (alcoholic and non-alcoholic) prices is larger in Chile than in Argentinean and Brazilian, c) inertial inflation of education is larger in Brazil than in Chile and Argentina, but it is larger in Chile than in Argentina, and d) household and equipment inertial inflation is larger in Chile than in Brazil and Argentina.

Measuring persistence (anti-persistence) by the positive (negative) fractionally integrated coefficient, our results imply that: a) Brazilian headline inflation exhibits persistence behaviour, but not Argentina, b) alcoholic beverages and tobacco display long-memory behaviour in Chile, c) clothing and health inflation display long-memory in Brazil, but only short memory in Argentina and Chile, d) household and equipment inflation show persistent behaviour in Argentina, although anti-persistent behaviour in Brazil and e) persistence of miscellaneous goods and services inflation in Argentina is larger than in Brazil and Chile, but in Chile is larger than in Argentina.

The impulse response functions associated to each estimated ARMA models measure how long it takes for a certain percent of the effects of a shock to die out. For instance, a) the quarter-life of headline occurs in 20,3 and 15 months in Argentina (second sample), Brazil and Chile, while its half-life takes 29, 15 and 13 months, respectively, b) the quarter, half and full life of food and non-alcoholic beverages needs i) 13, 14 and 37 months, respectively, in Argentina (second sample), ii) 24, 37 and over 100 periods, respectively, in Brazil, and iii) 13, 13 and 37 months, respectively, in Chile.

\section{V.1. Further extensions}

This research can be extended in various ways. First, the S-ARMA (or S-ARFIMA) models can be estimated adjusting the corresponding series by their trend (determined by the Hodrick and Prescott or the Baxter and King filters); it would take into account that the mean is not constant, but follows a trend (the one determined by the chosen filter).

Second, the whole set of models based on the Akaike, the Hannan-Quinn and the Schwarz information criterion could be evaluated in order to forecast indirect inflation (aggregate specific-component inflation to obtain headline inflation). Third, ARDL (autoregressive distributed lag), GARCH (generalized autoregressive conditional heteroskedasticity) or the Markov-Switching ARFIMA (with multiple inflation regimes) models could be applied as well.

Fourth, the role of the nominal exchange rate and the involved pass-through to the headline and sectoral inflation rates might be evaluated adding the variations of the nominal exchange rate as an exogenous regressor of the ARMA (ARFIMA) model. Also, inflation expectations could be added to the model taking into account that, in inflation targeting countries, a rise in inflation expectations are a device to contractionary monetary policies that aim to reduce inflation. Additionally, the dynamics of the stock returns could be related more to specific sector inflation than to the variation of the 
general prices. Also, stock prices might be more correlated to certain prices and, thus, the stock return-inflation puzzle could be analysed adding as explanatory variables a specific sector inflation.

Fifth, outliers could be considered stochastic in the sense that they change inflation not only in a certain period, but that they have time-effects depending on the data generation process of the corresponding variable (up to now, they are assumed deterministic). Finally, regarding the role of headline and sectoral inflation on financial markets, the stock return-inflation puzzle could be tested taking into account not only the headline inflation, but also the component of inflation that is more related to the prices of the firms that are listed in the stock markets. 


\section{References}

Agénor, P. R. (2004). The economics of adjustment and growth. San Juan: La Editorial UPR.

ATE-INDEC (2014). No somos cómplices de la mentira: Los trabajadores del INDEC denuncian la destrucción de las estadísticas públicas tras siete años de intervención. Ciudad Autónoma de Buenos Aires: CTA Ediciones.

Balcilar, M., Gupta, R. \& Jooste, C. (2016). Analyzing South Africa's inflation persistence using an ARFIMA model with Markov-switching fractional differencing parameter. University of Pretoria, Department of Economics Working Paper Series 40 50, 47-57.

Barros, J. R. M. de (2010). The impact of the international financial crisis on Brazil (ARI). Analyses of the Elcano Royal Institute (ARI), $\mathrm{N}^{\circ} 38$. Area: International Cooperation \& Development.

Batini, N. (2006). "Euro area inflation persistence". Empirical Economics 31, 977-1002.

BCRA (2016). Monetary policy report- May 2016. Argentinean Central Bank Monetary Policy Reports.

Berganza, J. C., Del Rio, P. \& Borrallo, F. (2016). Determinants and implications of low global inflation rates. Banco de España, Documentos Ocasionales.

Bermingham, C. \& D'Agostino, A. (2011). Understanding and forecasting aggregate and disaggregate price dynamics. European Central Bank, Working Paper № 1365.

Berumen, E. \& Beker, V. A. (2011). "Recent developments in price and related statistics in Argentina". Statistical Journal of the IAOS 27, 7-11.

Bourbonnais, R. \& Maftei, M. M. (2012). "ARFIMA Process: Tests and Applications at a White Noise Process, A Random Walk Process and the Stock Exchange Index CAC 40". Economic Computation and Economic Cybernetics Studies and Research, 46(1).

Boyd, J. H., Levine, R. \& Smith, B. D. (2001). "The impact of inflation on financial sector performance". Journal of Monetary Economics 47, 221-248.

Buelens, C. (2012). "Inflation forecasting and the crisis: Assessing the impact on the performance of different forecasting models and methods". Economic Papers, $\mathrm{N}^{\circ} 451$, $1-35$.

Canavese, A. J. (1985). Impuesto inflacionario, rezagos fiscales e hiperinflación. Asociación Argentina de Economía Política (AAEP).

Capistrán, C. \& Ramos-Francia, M. (2006). Dinámica de la inflación en México: Una caracterización utilizando la nueva curva de Phillips. Banco de México. Documento de Investigación 15.

Carlin, W. \& Soskice, D. (2009). "Teaching Intermediate Macroeconomics using the 3Equation Model". In Fontana, G. \& Setterfield, M. (eds.) Macroeconomic Theory and Macroeconomic Pedagogy (pp.13-35). London: Palgrave Macmillan.

Charemza, W. W., Hristova, D. \& Burridge, P. (2004). "Is inflation stationary?". University of York. 
Cogley, T. \& Sargent, T. J. (2001). "Evolving Post-World War II US Inflation Dynamics". In Bernanke, B. S. \& Rogoff, K. (eds.) NBER Macroeconomics Annual 2001, Vol. 16 (pp-331-388). Massachusetts: MIT Press.

Cottani, J. \& Oliveros-Rosen, E. (2016). "Inflation targeting in Latin America: What have we learned?". S\&P Global Ratings, Economic Research.

D’Amato, L. \& Garegnani, M. (2013). "¿Cuán persistente es la inflación en Argentina?: Regímenes inflacionarios y dinámica de precios en los últimos 50 años". En D'Amato, L., López Enciso, E. \& Ramírez Giraldo, M. T. (eds.) Dinámica inflacionaria, persistencia y formación de precios y salarios (pp. 91-115). México, D.F.: Centro de Estudios Monetarios Latinoamericanos (CEMLA).

D'Amato, L., Garegnani, M. \& Sotes Paladino, J. (2007). Inflation persistence and changes in the monetary regime: The Argentine case. Banco Central de la República Argentina, Working Papers (23) 1, 127-167.

Dany-Knedlik, G. \& Holtemöller, O. (2017). Inflation dynamics during the financial crisis in Europe: Cross-sectional identification of long-run inflation expectations. IWH Discussion Papers, $\mathrm{N}^{\circ} 10$.

Franses, P. H. \& Ooms, M. (1997). "A periodic long-memory model for quarterly UK inflation". International Journal of Forecasting, 13(1), 117-126.

Franta, M., Saxa, B. \& Smidkova, K. (2007). Inflation persistence: Euro area and new EU member states. European Central Bank, Working Paper Series No 810.

Gadea, M. \& Mayoral, L. (2006). "The persistence of inflation in OECD countries: A fractionally integrated approach". International Journal of Central Banking, 2(1), 51105.

Gallagher, L. A. \& Taylor, M. P. (2002). "The stock return-inflation puzzle revisited". Economics Letters, 75 (2), 147-156.

Gillis, M., Perkins, D. H., Roemer, M. \& Snodgrass, D. R. (1987). Economics of development. New York and London: WW Norton \& Company, Inc.

Gomes, C. da S. \& Leme, M. C. da S. (2011). "An analysis of the degrees of persistence of inflation, inflation expectations and real interest rate in Brazil". Revista Brasileira de Economia 65, 289-302.

Gujarati, D. N. (1995). Basic econometrics (3rd ed.). New York: McGraw-Hill International Editions.

Gutierrez, R. \& Dabús, C. (1989). "El ciclo inflacionario argentino, 1970-1988". Estudios económicos 7, 1-14.

Heymann, D. (1986). "El debate sobre las causas de la inflación". Revista de la CEPAL, No 28, 67-98.

Kouretas, G. P. \& Wohar, M. E. (2012). "The dynamics of inflation: A study of a large number of countries". Applied Economics, 44(16), 2001-2026.

Kwiatkowski, D., Phillips, P. C., Schmidt, P. \& Shin, Y. (1992). "Testing the null hypothesis of stationarity against the alternative of a unit root: How sure are we that economic time series have a unit root?". Journal of Econometrics, 54(1-3), 159-178. 
Levin, A. T. \& Piger, J. M. (2004). Is inflation persistence intrinsic in industrial economies? European Central Bank, Working Papers $N^{\circ} 334$.

Mignon, V. (1997). Marchés financiers et modélisation des rentabilités boursiéres. Bucharest: Economica Publishing House.

Mohaded, N. \& Gasparin, J. (2011). Persistencia inflacionaria en Argentina: Algunas reflexiones para el período 1955-73. Asociación Argentina de Economía Política (AAEP).

Noriega, A. E. \& Ramos-Francia, M. (2009). On the dynamics of inflation persistence around the world. Banco de México, Documento de Investigación.

Ozturk, N. \& Karagoz, K. (2012). Relationship between inflation and financial development: Evidence from Turkey. International Journal of Alanya Faculty of Business, 4(2), 81-87.

Pérez, A. \& Ruiz, E. (2002). "Modelos de memoria larga para series económicas y financieras". Investigaciones Económicas, 26(3), 395-445.

Roache, S. K. (2014). Inflation persistence in Brazil -a cross country comparison. International Monetary Fund.

Saavedra-Rivano, N. (1988). La tasa de interés en procesos inflacionarios e hiperinflacionarios. Asociación Argentina de Economía Política (AAEP).

Stock, J. H. \& Watson, M. W. (2016). "Core inflation and trend inflation". Review of Economics and Statistics, 98(4), 770-784.

Totonchi, J. (2011). "Macroeconomic theories of inflation". International Conference on Economics and Finance Research, 459-462.

\section{Appendixes}

\section{VII.1. Evolution of the CPI and CPI sectoral prices in the ABC countries}

Figure A1 displays the evolution of consumer price indexes and their specificcomponent in Argentina, Brazil and Chile. It tells us for the Argentinean first sample that a) Argentina experienced price stability during the time of the exchange rate peg, b) food and beverages, clothing and household equipment had a deflationary trend after 1996, c) headline inflation turned negative after 1999, d) transport and communication prices trended upwards and stabilized only after the year 2000, e) health and education prices remained mostly constant in the period previous the end of the convertibility regimen and f) household prices and miscellaneous goods and services and recreation prices do not show a clear pattern before 2001. Argentinean prices show a clear upward trend after the year 2005, with sectoral inflation moving mainly in line with headline inflation.

In Brazil, headline, cloth, health and miscellaneous prices exhibit a similar trend since 2009, while food and beverage, transport, housing and household and equipment show a similar upward trend after 2014. In Chile, headline inflation has been lower than 5.89\% inter-annual since 2009, with peaks between May 2014 and December 2014. Headline, food and beverages (alcoholic and non-alcoholic) and restaurant and hotel prices display similar upward trend since November 2009. Clothing, communication and recreation and culture decreased up to November 2013. While clothing and 
communication prices are still diminishing, recreation and culture showed a positive trend after February 2017. Inflation of education, housing and miscellaneous goods and services exhibit a positive trend after August 2013.

Figure A1: CPI and CPI sectoral price indexes in the ABC countries (In logarithms)
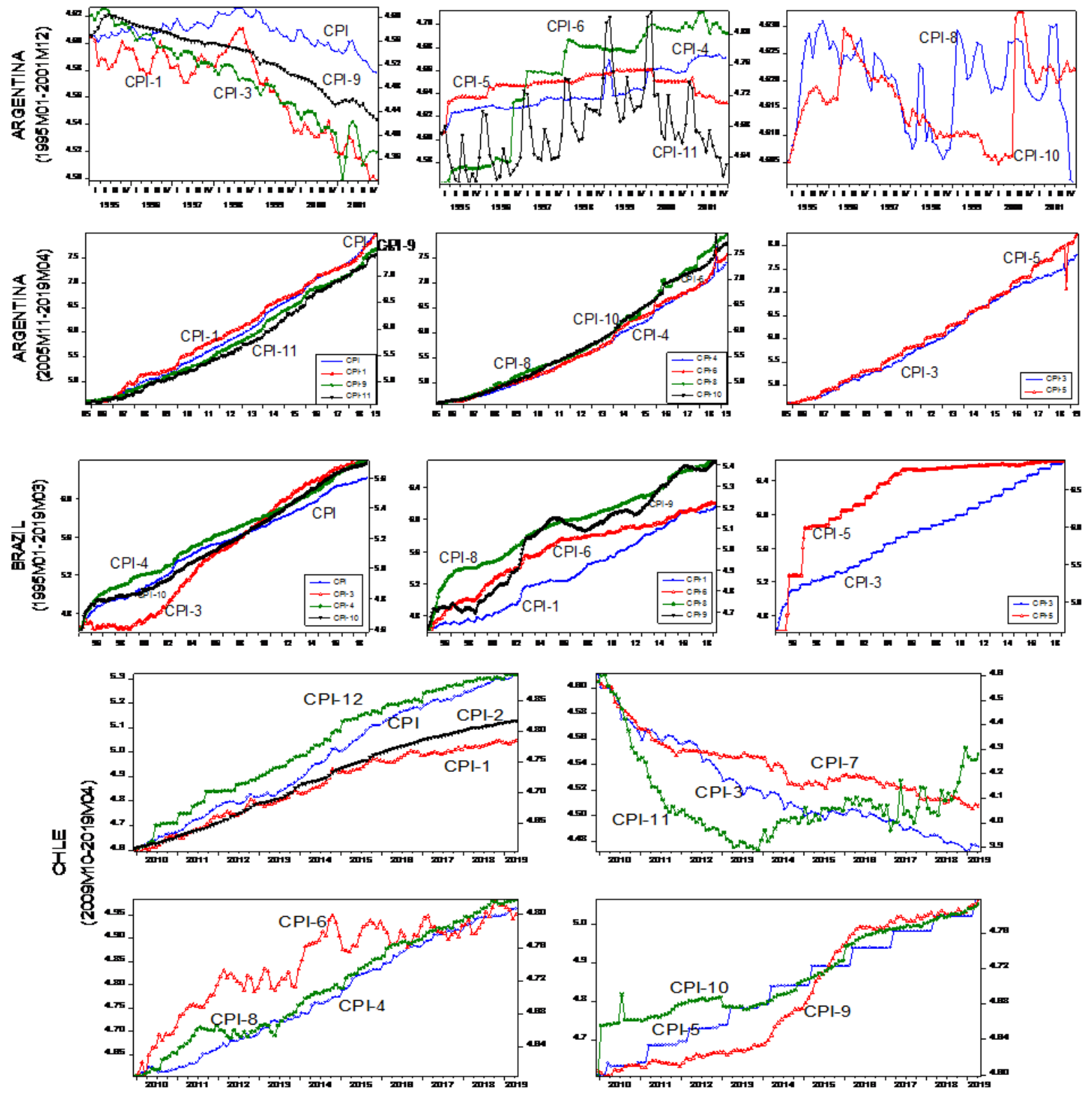

Note: On the right axis are CPI-3, CPI-6 (Argentinean first sample), CPI, CPI-8 and CPI-5 (Argentinean second sample), CPI-3, CPI-9 and CPI-7 (Brazil), and CPI, CPI-3 and CPI-4 (Chile).

\section{VII.2. Impulse Response Functions}

Figure A2 shows, for the relevant periods, similar impulse response functions for each country. Inflation and sectoral inflation variables with similar impulse response functions are a) for the Argentinean 1995 - 2001 sample: i) headline, health, education, housing and recreation, ii) food and beverage, transport and 
communication, household and equipment and miscellaneous goods and services; b) for the Argentinean 2005 -2019 sample: i) headline, education and recreation, ii) food and beverage, health, transport and communication, household and equipment and miscellaneous goods and services and iii) clothing and housing; c) for Brazil: i) headline, clothing, health, housing, household and equipment and miscellaneous goods and services and ii) food and beverage and transport, and d) for Chile: i) headline, food and non-alcoholic beverage, alcoholic beverage and tobacco, transport, communication, housing and miscellaneous goods and services and ii) clothing, household, recreation and culture and restaurant and hotels.

Figure A2: Impulse response functions in the $A B C$ countries

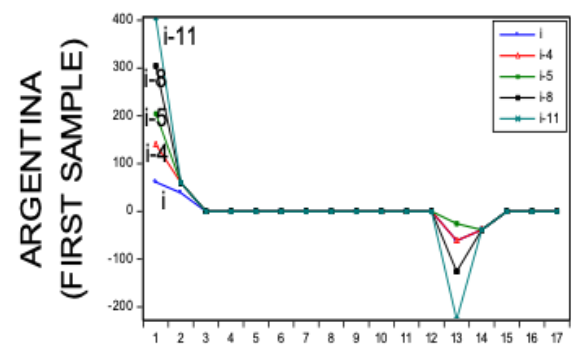

a) stacked
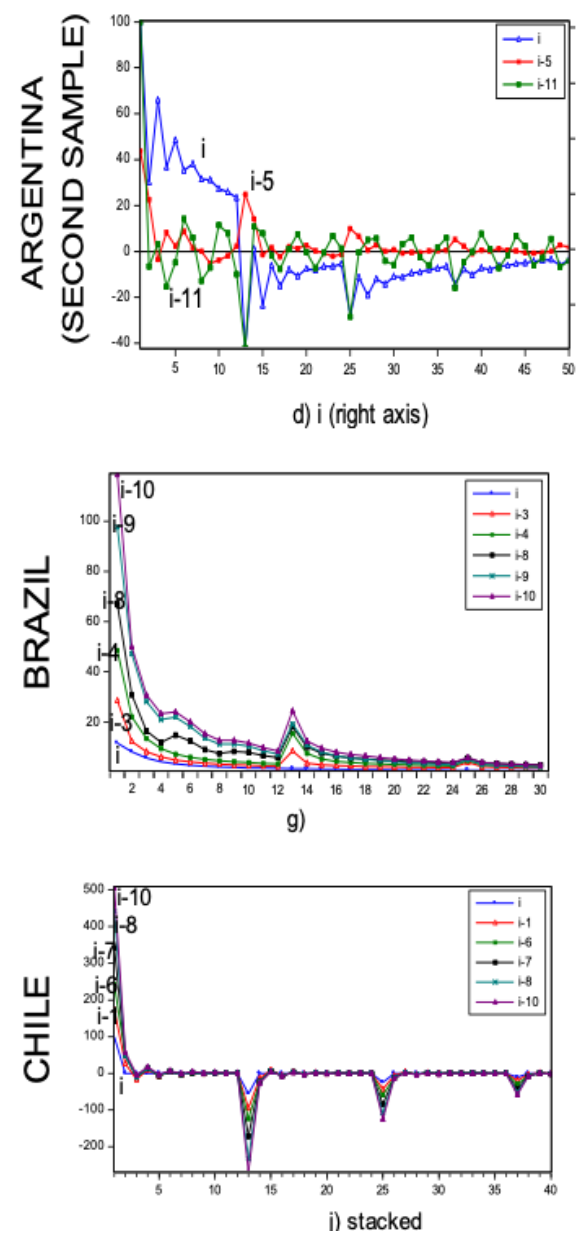

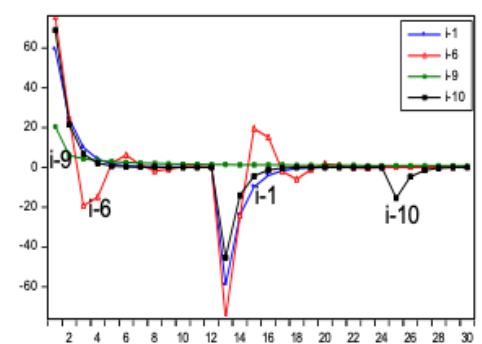

b)

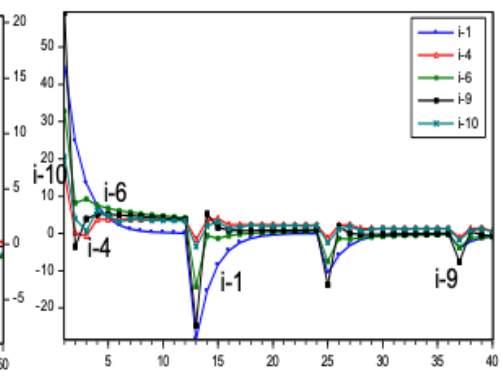

e)

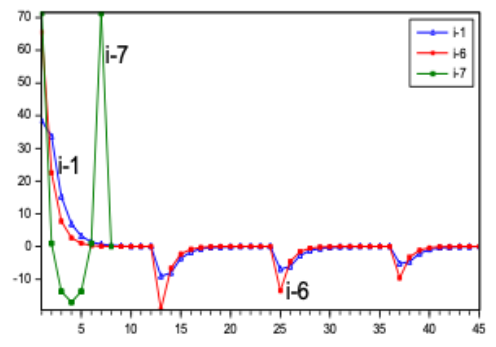

h)

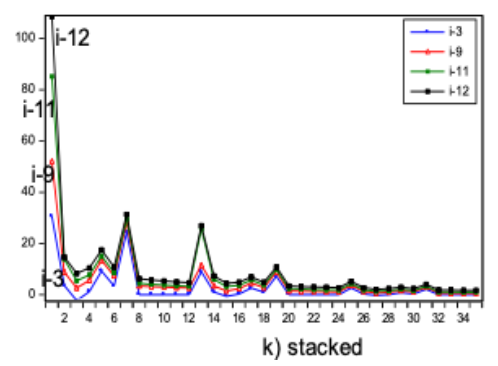

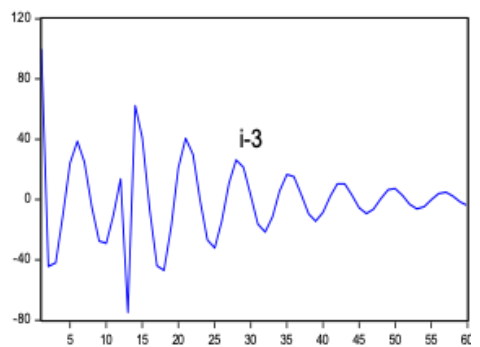

c)

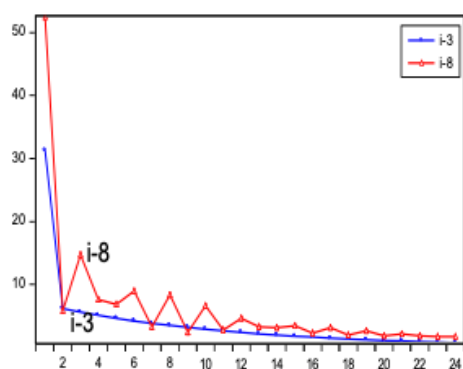

f)
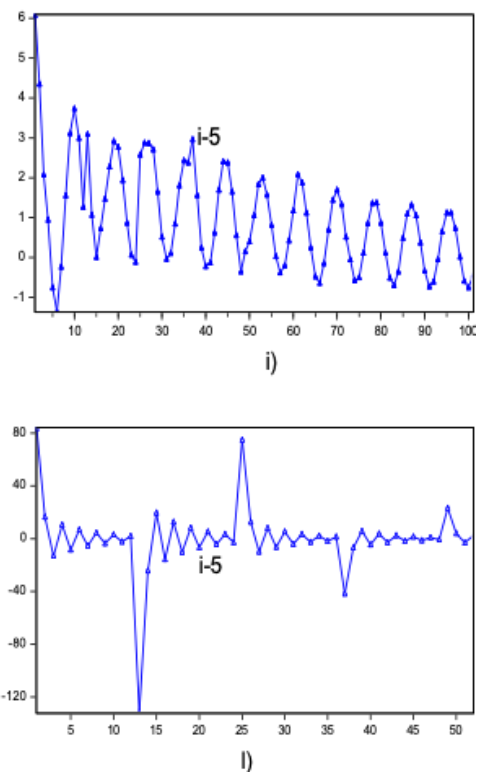

Note: The responses have been normalized to their total (or maximum) cumulative effect. Stacked charts plot the data that are sums of the series in the group. 